\title{
Comunicação e memória em tempos de repressão: uma análise interdisciplinar de Memórias do cárcere e Primavera con una esquina rota
}

Adriana Coelho Florent Mestra de conferências da Universidade de Paris 8 E-mail: florentphilippie@aol.com

Histórias que contam a vivência de prisioneiros políticos em tempos de repressão colocam de maneira intensa a questão da memória. O que se deve lembrar, o que é melhor esquecer? Como resistir à pressão exercida pela tortura, física e moral, e não revelar fatos, nomes, rostos, gravados na memória? De que modo evitar o esquecimento da vida em liberdade, cujas imagens cada vez mais distantes acabam por parecer irreais ao prisioneiro isolado? $\mathrm{O}$ que fazer com as marcas adquiridas durante a experiência carcerária: apagá-las ou expô-las para sobreviver?

Todas estas questões estão presentes de maneira instigante em duas obras literárias latino-americanas: Memórias do cárcere, de Graciliano Ramos ${ }^{1}$, e Primavera con una esquina rota (Primavera por uma esquina rota), de Mario Benedetti². Embora nos forneça índices essenciais, a análise puramente literária não basta para abordarmos tais questões. Além de seu necessário enquadramento em determinados contextos históricos e políticos, devemos, ao abordá-las, levar igualmente em conta seus aspectos psicológicos. Quanto a este último aspecto, referimo-nos essencialmente aos trabalhos de pesquisa pioneiros sobre os efeitos da tortura que têm sido realizados por Françoise Sironi e o centro de etnopsiquiatria Georges-Devéreux ${ }^{3}$.

No dia três de março de 1936, o romancista Graciliano Ramos foi detido por um tenente do exército em seu domicílio na cidade de Maceió. O fracasso

1. RAMOS, Graciliano. Memórias do cárcere. Rio de Janeiro: Record, 1987. v. I e II.

2. BENEDETTI, Mario. Primavera con una esquina rota (Primavera por uma esquina rota). Barcelona: Edhasa, 1992.

3. Centro Georges-Devéreux (centro universitário de ajuda psicológica), Universidade de Paris 8, 2 , rue de la liberté, 93 526 - Saint-Denis. 
da revolta comunista de 1935 contra o governo provisório de Vargas, instalado no poder desde 1930, havia despertado uma onda de violenta repressão em todo o País. Embora os responsáveis pelas insurreições desencadeadas no Nordeste e no Rio de Janeiro fossem os militares ligados à direção do Partido Comunista, os membros ou até mesmo os simples simpatizantes da Aliança Nacional Libertadora - ampla frente de oposição ao poder - foram perseguidos e detidos. A prisão de Graciliano, assim como sua liberação dez meses depois, em janeiro de 1937, foram atos arbitrários do poder, que tiveram conseqüências determinantes em sua vida e em sua obra. Nunca houve um processo contra Graciliano Ramos, nem sequer um interrogatório. A única acusação

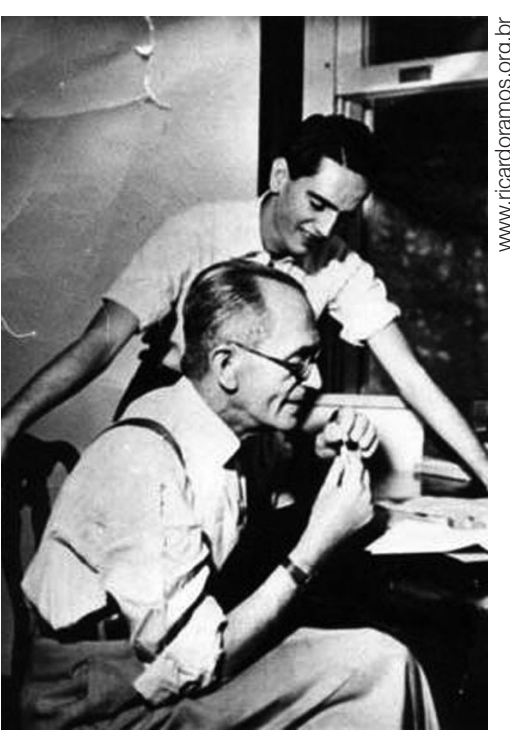

Graciliano Ramos e seu filho Ricardo que pesou contra ele, feita pelo General Newton Cavalcanti, foi a de ser comunista. Ora, se ele mantinha de fato contatos com o comunismo através de seus filhos mais velhos, membros da Juventude Comunista, ou de amigos próximos do PCB, como Raquel de Queiroz, o escritor só se tornaria membro do Partido Comunista em 1945. Mas naquela época - como em outras mais recentes - estes contatos, somados a uma denúncia anônima, eram quanto bastava para se prender alguém.

Com efeito, anos mais tarde, o escritor alagoano transformaria sua experiência em um doloroso livro de memórias que permaneceu inacabado. Memórias do cárcere foi publicado em 1953, sete meses após a morte do autor, e o seu êxito imediato persiste até hoje. Embora o pacto autobiográfico esteja explicitado tanto pelo título quanto pelo início da obra, não se trata apenas de memórias. Recorremos aqui à definição do gênero autobiográfico estabelecida por Philippe Lejeune nestes termos: "Récit rétrospectif en prose qu'une personne réelle fait de sa propre existence, lorsqu'elle met l'accent sur sa vie individuelle, en particulier sur l'histoire de sa personnalité"4.

Aproveitando um material heterogêneo, que inclui desde testemunhos, confissões, cartas, reflexões gerais até trechos de canções, Graciliano recorre a um estilo próprio à ficção, como já havia feito no seu primeiro livro autobiográfico, Infância. Valentim Facioli observa a respeito do narrador em Memórias do cárcere: "Há evidente empatia do narrador-autor no tempo da narração com

4. LEJEUNE, Philippe. Le pacte autobiographigue. Paris, Senil, 1975. p. 14.

5. FACIOLI, Valentim. Dettera: ilusão e verdade - Sobre a (im)propriedade de alguns narradores de Graciliano Ramos. Revista do Instituto de estudos brasileiros, São Paulo, n. 35, p. $65,1993$. sua posição no tempo dos acontecimentos narrados, num movimento de continuidade e persistência. $\mathrm{O}$ autor-narrador continua idêntico à vítima da prisão de anos antes.".

Muitos episódios foram elaborados como se fossem contos, de tal modo que o narrador - e com ele o leitor - parece estar vivendo os fatos na medida em que são descritos, numa tentativa para abolir a distância entre o memorialista e o prisioneiro. 
De maneira quase simétrica, Primavera con una esquina rota de Mario Benedetti, publicado em 1982, apresenta-se explicitamente como um romance, mas inclui numerosos trechos autobiográficos. De fato, o escritor uruguaio foi levado ao exílio durante a onda de repressão que antecedeu e anunciou o golpe de estado de 1973, quando as Forças Armadas afirmaram sua vitória sobre o MLN - Movimento de Libertação Nacional tupamaro, cuja ação subversiva contra o poder não podia ser mais tolerada. Fundado por Raúl Sendic, Jorge Manera e Julio Marenales em 1963, o MLN atuou inicialmente através de ações pontuais, como o roubo de brinquedos redistribuídos entre as crianças pobres, ou o incêndio de canaviais em solidariedade à luta dos cortadores de cana. Pouco a pouco, com o endurecimento da repressão e a degradação da situação econômica, o meio estudantil também aderiu ao movimento, cujas estratégias de luta passam a ser mais radicais: o seqüestro e o assassinato de Dan Mitrione, agente da CIA e assessor da polícia uruguaia em 1970, tornaram essa evolução irreversível. Durante o ano de 1972, os tupamaro foram quase todos presos ou expulsos, e só puderam voltar a atuar no espaço político uruguaio cerca de vinte anos mais tarde.

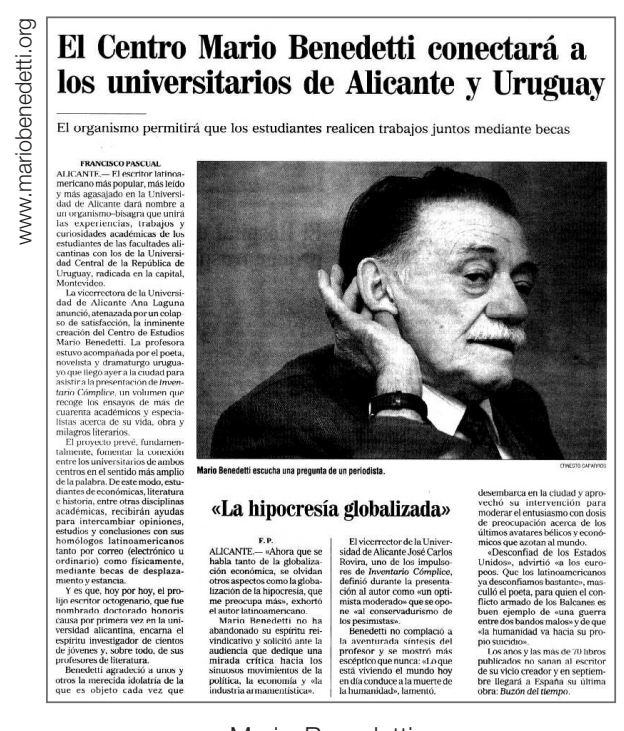

Mario Benedetti

Como na era de Getúlio, os movimentos moderados, reunidos numa frente ampla (Frente Amplio) durante a campanha eleitoral que antecedeu o golpe, foram arrastados pela repressão. Durante toda a década de 1970, com sua própria vivência do exílio, Mario Benedetti foi acrescentando os testemunhos de conhecidos e familiares expulsos, presos, torturados, por vezes assassinados pela ditadura uruguaia. Essa soma de experiências serviu de base para a elaboração de Primavera con una esquina rota. A heterogeneidade da obra, cujos capítulos alternam seqüências narrativas na terceira pessoa, diários, cartas, monólogos interiores de personagens encarcerados ou exilados, crônicas autobiográficas ou mesmo redações infantis reinventadas, reflete de modo eficaz as conseqüências da repressão sobre o indivíduo, particularmente no que diz respeito à prisão e à tortura.

Tanto na obra de Graciliano como na de Benedetti, podemos observar a tentativa de fragmentação da identidade do elemento subversivo que ameaça pôr em causa o discurso autoritário imposto pela ditadura e simultaneamente os esforços dos prisioneiros para resistir a esta tentativa. Em ambos os casos, o que está em jogo é a capacidade de controlar os mecanismos da memória no seu constante vaivém entre esquecimento e lembrança.

Inicialmente, tentaremos compreender as estratégias e os objetivos da repressão ao recorrer à tortura, tais como se apresentam nas obras estudadas. 
Veremos em seguida os diferentes modos de comportamento daqueles que, tendo sido torturados, podem transformar-se, conforme as circunstâncias, em heróis ou em traidores. Por fim, será possível observar como a memória pode ser resgatada através da literatura, que representa para os dois escritores o principal modo de resistência contra a opressão.

Como indica Françoise Sironi, os métodos de tortura empregados pelo Estado autoritário não apresentam diferenças notáveis, por mais diversos que sejam os contextos históricos, culturais ou geográficos ${ }^{6}$. Essa semelhança é atribuída pela autora aos acordos de cooperação militar e técnica estabelecidos entre os países que praticam a tortura de modo sistemático. Assim, a partir de 1960, as ditaduras latino-americanas receberam apoio da polícia militar francesa que havia participado da guerra da Argélia, bem como da CIA americana. A autora propõe as seguintes categorias: a dor (espancamentos, chicotadas, choques elétricos, unhas arrancadas); as privações (sede, fome, falta de sono, falta de ar, de movimento, de presença humana); a transgressão de tabus culturais, em particular aqueles ligados ao sexo; por fim, o terror (ameaças, execuções simuladas, torturas ou assassinatos de amigos ou familiares) ${ }^{7}$. Nas duas obras escolhidas, podemos observar exemplos de todas as categorias citadas, mas o mecanismo do terror fica claramente perceptível através do seguinte episódio, narrado em Memórias do cárcere:

[Percebi] ao fundo [do cubículo] três rapazes [...]. Eram da marinha, e dois vestiam farda. $\mathrm{O}$ terceiro, quase criança, tinha o busto nu, escoriado e contuso; manchas alargavam-se, lanhos cruzavam-se no peito, no dorso, nas costelas, sinais vermelhos, com certeza novos, outros violáceos, azuis, negros a revelar que o garoto tinha sido maltrato várias vezes. [...]

Um grito lá embaixo nomeou alguém - e o moço das feridas estremeceu, muito pálido. [...]

- Fulano de Tal. Polícia.

Entre o chamado e a última palavra uma pausa se alargara, talvez com o intuito perverso de dar ao infeliz uma esperança tênue. Pata macia de gato acariciando um rato. Em horas assim este se encolhe cheio de pavor, agarra-se a ilusões fugitivas, busca imaginar ocorrências vulgares: ida à secretaria, visita inesperada, uma carta improvável. Engana-se voluntariamente, esforça-se por afastar a lembrança das torturas, ali visíveis na pele, desalenta-se ouvindo as sílabas fatais, e a significação delas surge clara: perguntas invariáveis multiplicadas, a exigir denúncias, a teimosia silenciosa do paciente punida com sevícias: golpes de borracha, alicate nas unhas, o fogo do maçarico destruindo carnes. Quando a horrível ordem soou, o rapaz se ergueu aflito, o rosto lívido crispado:

- Ah! Meu Deus! Não agüento mais. Vão matar-me ${ }^{8}$.

6. SIRONI, Françoise. Bourreaux et victims. Paris: Odile Jacob, 1999. p. 16-17.

7. Ibid., p. 27-30.

8. RAMOS, op. cit., p. 357-358, v. I.
A passagem do pretérito para o presente leva o leitor a identificar-se com o marinheiro, seguindo assim os passos do narrador. Mas ao desvendar o mecanismo do terror, que para torturar emprega a própria lembrança das sessões de tortura, o autor impede que nos deixemos simplesmente levar pela emoção, compelindo-nos a refletir sobre ela. 
A escolha de tais métodos, longe de ser aleatória, corresponde a objetivos bem definidos, os quais surgem em determinado momento histórico.

De fato, nas reações do narrador de Memórias do cárcere podemos discernir o salto qualitativo e quantitativo do emprego da tortura na América Latina no final da década de 1930, sob influência direta do fascismo e do nazismo estabelecidos na Europa. O emprego da violência para a preservação do poder é bastante habitual em toda a história latino-americana. Assim, ao ter desagradado às autoridades locais por sua atuação rigorosamente imparcial como secretário da Educação do estado de Alagoas, Graciliano Ramos não espera escapar ileso a sua ira. Mas quando imagina as represálias exercidas contra ele, supostamente por membros do Partido Integralista, que passa a dominar o cenário político da época, refere-se ainda ao comportamento tradicional dos coronéis nordestinos: "Foi o que imaginei: uma agressão pública, muitos integralistas atacando-me, furando-me, partindo-me as costelas, os braços e a cabeça".

Ora, a repressão organizada contra os comunistas após a insurreição de 1935 inaugura uma nova era na história da opressão no Brasil. De fato, o chefe de polícia do Rio de Janeiro, Filinto Müller ${ }^{10}$, passa a usar os métodos empregados pela Gestapo alemã, com a qual colabora regularmente, como demonstra o caso da prisão de Olga Benario, companheira alemã de Luís Carlos Prestes, com quem Graciliano travou conhecimento num dos cárceres da capital ${ }^{11}$.

Não se trata apenas de punir o desacato à autoridade, mas de incutir a nova ordem moral e política, como indica o próprio Getúlio Vargas em depoimento prestado a sua filha:

A repressão tinha de ser drástica para poder satisfazer à opinião pública, revoltada ante a brutalidade dos fatos [a tentativa de insurreição de 1935], e também restabelecer a sensação de segurança de que todos necessitam para poder trabalhar, produzir e viver sem sobressaltos. Infelizmente, à sombra dessa proteção dada pelo Governo, com as leis de exceção, muitas injustiças foram cometidas, difíceis de reparar imediatamente. Houve quem se aproveitasse do momento para vingar-se de desafetos políticos, sob a acusação de idéias subversivas ${ }^{12}$.

Notemos que Vargas procura restabelecer a sensação de segurança da coletividade, e não garantir a segurança de cada indivíduo. Tais foram também as razões evocadas para a declaração de estado de sítio, do fechamento do congresso e, finalmente, do golpe de 1937 que levaria à fundação do Estado Novo. Em suma, os excessos da repressão são o preço a pagar para se obter uma sociedade talvez injusta, mas segura e producente.

O objetivo explicitamente reivindicado por um governo que decide recorrer à tortura é em geral de natureza pragmática. Algumas informações são consideradas indispensáveis ao combate à subversão, que ameaça a sociedade como um todo: identidade das diferentes organizações políticas e de seus membros, localização de esconderijos e locais de reunião, planos de ação e propaganda, meios de financiamento. Diante da recusa dos prisioneiros em colaborar com o organismo encarregado de restabelecer a ordem social - ou em última análise
9. Ibid., p. 42.

10. Sobre a atuação de Filinto Müller, chefe da polícia do Rio de Janeiro encarregado por Getúlio Vargas de reprimir o comunismo, ver: CARONE, Edgar. A República Nova (1930-1937). São Paulo: Difel, 1974, p. 337; SILVA, Hélio. 1935, a revolta vermelha. São Paulo: $\mathrm{Ci}$ vilização brasileira, 1969, p. 305-306; e MORAIS, Fernando. Olga: a vida de Olga Benario Prestes, judia comunista entregue a Hitler pelo governo Vargas. São Paulo: AlfaOmega, 1986. p. 107.

11. RAMOS, op. cit., p. 224, v. I.

12. PEIXOTO, Alzíra Vargas do Amaral. Getúlio Vargas, meu pai. Porto Alegre: Globo, 1960. p. 140-141. 
13. Ver os pormenores deste episódio em MORAIS, op. cit.

14. Citado por Montaigne em seus ensaios (livro 2, capítulo 5). Sobre o mesmo tema, consultar a obra de Augustin Nicolas, membro do parlamento de Besançon em 1682 (NICOLAS, Augustin. Si la torture est un moyen súr à vérifier les crimes secrets. Marselha: Laffitte, 1982).

15. BENEDETTI, Mario. Primavera por una esquina rota. Barcelona: Edhasa, 1992, p.121.

16. RAMOS, op. cit., p. 132, v. II. a paz, pois se trata de uma guerra -, resta apenas optar pela tortura. É preciso saber escolher dos males o menor.

Seria realmente a tortura o meio mais rápido e mais eficaz de se obter uma informação? Talvez os interrogatórios aos quais foram submetidos Rodolfo Ghioldi, secretário do Partido Comunista Argentino, e Antonio Maciel Bonfim, secretário-geral do PCB desde 1934, ambos presentes em Memórias do cárcere, tenham de fato contribuído para o desmantelamento da insurreição de $1935^{13}$. A colaboração de serviços internacionais de inteligência secreta, bem como a espionagem e a infiltração parecem-nos, entretanto, elementos bem mais determinantes para o êxito da polícia de Filinto Müller.

Desde a antiguidade, segundo a máxima de Publius Sirus, sabemos que etiam innocentes cogit mentiri dolor. a dor leva até os inocentes a mentir ${ }^{14}$. A confusão mental do prisioneiro submerso pela dor e pelo medo pode levá-lo a revelar segredos, mas também a inventá-los, ou a calá-los para sempre, devido à loucura ou à morte.

Por outro lado, a confissão, mesmo falsa, representa a vitória da repressão na medida em que a legitima. Nesse caso, o silêncio do prisioneiro põe de fato em causa tal legitimação. Em uma carta dirigida a Don Rafael, seu pai, Santiago, personagem da obra de Benedetti, escreve:

¿Te asombras si te digo que aún no sé si mi callé por convicción o por cálculo? Sí, por cálculo. Siempre miré que, mientras lo niegas todo, si te obstinas en decir que no y que no con la cabeza, con las manos, con los labios, con los ojos, con la garganta, los tipos igual te dan como en bolsas, claro, pero a veces notas que en el fondo sospechan que les estás diciendo la verdad, o sea, que no sabes nada de nada; ah, pero en cambio si flaqueas y dices una cosa mínima, una pavada que acaso no les sirva para nada y con la que no jodes a nadie, entonces la actitud cambia, porque, a partir de ese momento, creen que sabes muchísimo más, y ahí sí que te amasijan, se ensañan contigo. Si niegas permanentemente, te van a reventar, es lógico, pero también es posible que, a partir de cierto día, te dejen tranquilo, porque quizá se convenzan de que efectivamente no sabes nada. [...] De todos modos, estoy conforme, porque nadie cayó por una flojera mía ${ }^{15}$.

Estamos aqui diante da figura clássica do militante profissional que resiste a todas as formas de interrogatório. No entanto, devemos levar em conta o fato de que a tortura, a partir de 1930, passou a ser aplicada sistematicamente a todos os prisioneiros, estivessem eles diretamente envolvidos em movimentos de guerrilha ou não. Alguns presos por engano surgem assim em Memórias do cárcere, como o beato antiateu, o alto funcionário ou o russo foragido do regime soviético, detido unicamente por causa de sua nacionalidade. $\mathrm{O}$ caso mais significativo das intenções reais do sistema repressivo é, sem dúvida, o de Tiago, membro da marinha britânica nascido no Brasil. Devido a uma altercação com um motorista de táxi no Rio de Janeiro, durante uma permissão, Tiago é denunciado como comunista. Embora inocentado, é condenado ao encarceramento na Colônia Correcional, pois, segundo o delegado, "não é bom que esse negócio seja contado lá fora" ${ }^{16}$. O narrador tenta encontrar uma explicação pertinente para o caso absurdo, e chega à seguinte conclusão: 
O governo se corrompera em demasia; para agüentar-se precisava simular conjuras, grandes perigos, salvar o país enchendo as cadeias. Mas as criaturas suspeitas [...] eram escassas, não davam para justificar medidas de exceção e arrocho, o temor público necessário à ditadura. Assim prendia-se um viajante alheio aos sucessos do Brasil. Os jornais aplaudiam. Na publicidade rumorosa, Tiago reunia-se aos outros, vago conspirador anônimo ${ }^{17}$.

As palavras de Vargas citadas anteriormente confirmam a verossimilhança desta hipótese. Podemos concluir então que o objetivo essencial do recurso à tortura nos estados totalitários é antes o de fazer calar do que o de fazer falar ${ }^{18}$. Aquele que contesta o discurso imposto, ou simplesmente difere dos padrões estabelecidos, é negado e deve ser marcado de maneira permanente. Don Rafael lembra a declaração de um dos diretores do presídio Libertad a respeito dos subversivos:

No nos atrevimos a liquidarlos a todos cuando tuvimos la oportunidad, y en el futuro tendremos de soltarlos. Debemos aprovechar el tiempo que nos queda para volverlos locos. Por lo menos fue franco, verdad? ${ }^{19}$

A desumanização faz parte deste processo de enlouquecimento deliberado: os prisioneiros passam a ser considerados não como seres humanos, mas como simples objetos. Em sua viagem de barco para a Colônia Correcional de Ilha Grande, o narrador de Memórias do cárcere encontra-se em presença de duas senhoras da família do diretor do presídio:

Estávamos ali, arrumados nas pranchas, com os nossos embrulhos e a nossa desgraça - e elas não nos viam. Lixo. Se quisessem levantar e andar, caminhariam bem, pois não tomávamos espaço, éramos coisas diminutas, rentes às tábuas. Passariam tranqüilas por cima de nós, machucar-nos-iam com as solas dos sapatos, como se fôssemos pontas de cigarro. [...] E se uma daquelas senhoras quisesse mijar? Esse pensamento burlesco um minuto me agravou os arranhões da goela, o desejo de rir. Nenhum motivo para acanharem-se, mijariam facilmente na rede de Macedo, no capote do Zoppo, na minha valise. Tão grandes e afastadas, assim próximas e miúdas, em cadeiras de vime! ${ }^{20}$

O duplo oxímoro empregado na última frase - próximas e afastadas, grandes e miúdas - ressalta a inversão de valores operada pelo totalitarismo. Por outro lado, ao nomear os seus próprios pertences e o de seus amigos, o narrador busca restaurar sua identidade, inserindo-se num grupo, embora se trate do grupo dos perdedores.

Desse modo, surge a possibilidade de fugir à lógica binária imposta pelos mecanismos da repressão: amigo ou inimigo, herói ou traidor, do lado do bem ou do lado do mal? A capacidade de resistência à tortura é absolutamente imprevisível, o que deveria impedir qualquer julgamento, pois como diz Don Rafael, "uno no sabe quién es realmente, cuán incinerable o incombustible es, hasta que no pasa por alguna hoguera"21. A partir do exemplo de Rodolfo Ghioldi, o narrador de Memórias do cárcere procura reconstituir mentalmente a experiência íntima do torturado:
17. Ibid., p. 132-133.

18. SIRONI, op. cit., p. 12.

19. BENEDETTI, op. cit., p. 89. Françoise Sironi refere-se a esta mesma declaração (SIRONI, op. cit., p. 148).

20. RAMOS, op. cit., p. 38-39.

21. BENEDETTI, op. cit. p. 90 . 


\begin{abstract}
O meu bom amigo [Ghioldi] demorou-se alguns dias perplexo, recobrou dificilmente a calma. Depois, às novas inquirições, notou que se havia conservado perfeitamente digno: as suas palavras não causariam dano a outros indivíduos. Guardei, porém, a lembrança daquela incerteza agoniada:

- Menti demais e já nem sei o que disse.

Resistência inconsciente, defesa instintiva, imensa teimosia a escorar a vontade inânime - depois a supressão da memória, nenhuma resposta à pergunta ansiosa: "Terei praticado uma infâmia?" Admiramos a coragem alheia, e nem pensamos que em difícil conjuntura ela própria se ignorou [...]. Imaginei naquela situação e naquela angústia alguém que houvesse fraquejado no torniquete: "Nem sei o que disse. Terei cometido infâmia?" Sim ou não. Como no jogo do cara-ou-cunho, a moeda oculta debaixo da palma. Súbito, a descoberta medonha - sim, e está um homem perdido, coberto de opróbrio, inteiramente impossível a reabilitação. Num caso ou noutro, ausência de culpa, ausência de mérito. Pensamos assim. E não evitamos o desprezo ou o entusiasmo. Rodolfo cresceu muito aos meus olhos. A energia involuntária deu-lhe maior prestígio que a inteligência revelada nos discursos longos ${ }^{22}$.

Ao analisar suas próprias reações, às quais associa o leitor pelo emprego da primeira pessoa do plural, Graciliano desvenda um dos mecanismos da repressão, que busca impor uma visão maniqueísta do mundo. Nesse caso, o próprio recurso à forma literária, através do discurso na primeira pessoa combinado com a multiplicidade dos pontos de vista, à heterogeneidade do material utilizado, à inserção de diálogos, monólogos interiores e pequenas histórias, representa um modo de resistência para os dois autores. O discurso do poder procura pôr em causa a existência de uma comunidade resistente à qual possa pertencer o prisioneiro: ou afirma sua completa destruição, ou, caso a confissão tenha sido arrancada, profetiza sua total rejeição.

Pelo contrário, nos casos em que o prisioneiro consegue recuperar a consciência de fazer parte de um grupo, o processo de fragmentação deflagrado pela tortura pode ser revertido.

Um dos caminhos para essa reversão passa pelas memórias. Ao elaborar um novo modelo terapêutico aplicável às pessoas que foram submetidas à tortura, Sironi insiste na importância da reconstrução intelectual de tais experiências: "c'est parce que l'atteinte de la capacité de penser est centrale sous la torture que la thérapie des victimes de torture doit être menée sous un mode intellectuel" ${ }^{\prime 2}$. Mesmo antes de haver recuperado a liberdade, o controle exercido sobre a memória e a recapitulação voluntária de lembranças positivas, ou mesmo negativas, contribuem para a sobrevivência mental dos prisioneiros. Tal é o método empregado por Santiago no isolamento de sua cela: "Hace unas semanas que descubrí el sistema. Antes, los recuerdos me asaltaban sin ordeno [...]. O sea, que los recuerdos me dominaban. Y una tarde pensé: por lo menos voy a liberarme de este dominio. Y a partir de entonces, soy yo quien dirijo mis recuerdos?24".

Do mesmo modo, outras atividades ligadas às capacidades rememorativas e criativas, tais como recitar poemas e canções, contar histórias, fictícias ou autobiográficas, ou mesmo redigir cartas são janelas abertas para a liberdade.
\end{abstract}




\section{Comunicação e memória em tempos de repressão • Adriana Coelho Florent}

Mas a escrita de cunho autobiográfico permanece sem dúvida a resposta mais eficaz no combate às conseqüências da tortura e da opressão. Ao sair da Colônia Correcional, o narrador de Memórias do cárcere não pode deixar de exprimir ao diretor sua sarcástica gratidão, por ter-lhe fornecido tão rico tema:

- Levo recordações excelentes, doutor. E hei de pagar um dia a hospitalidade que os senhores me deram.

- Pagar como? - exclamou a personagem.

- Contando lá fora o que existe na Ilha Grande.

- Contando?

- Sim, doutor, escrevendo. Ponho tudo isso no papel.

O diretor suplente recuou, esbugalhou os olhos e inquiriu carrancudo:

- O senhor é jornalista?

- Não, senhor. Faço livros. Vou fazer um sobre a Colônia Correcional. Duzentas páginas ou mais. Os senhores me deram assunto magnífico. Uma história curiosa, sem dúvida.

O médico enterrou-me os olhos duros, o rosto cortante cheio de sombras. Deume as costas e saiu resmungando:

- A culpa é desses cavalos que mandam para aqui gente que sabe escrever ${ }^{25}$.

O opressor, agora transformado em personagem, fragiliza-se e perde seu poder de influência sobre o oprimido. De mais a mais, o livro aqui projetado vai além de uma simples revanche contra a hospitalidade oferecida pela ditadura. Trata-se igualmente de resgatar a dívida contraída com relação aos companheiros de prisão, fazendo-os reviver à medida que o narrador vai pondo ordem no caos que, ao tê-lo atingido como indivíduo, havia contaminado a sociedade como um todo. No início da obra, o autor explica o que o levou, dez anos após os acontecimentos narrados, a dedicar-se ao árduo trabalho de reconstituição:

Formamos um grupo muito complexo, que se desagregou. De repente nos surge a necessidade urgente de recompô-lo. Define-se o ambiente, as figuras se delineiam, vacilantes, ganham relevo, a ação começa. Com esforço desesperado arrancamos de cenas confusas alguns fragmentos. [...] Nessas vacilações dolorosas, às vezes necessitamos confirmação, apelamos para reminiscências alheias, convencemonos de que a minúcia discrepante não é ilusão. Difícil é sabermos a causa dela, desenterramos pacientemente as condições que a determinaram [...]. Fiz o possível para entender aqueles homens, penetrar-lhes na alma, sentir as suas dores, admirar-lhes a relativa grandeza, enxergar nos seus defeitos a sombra dos meus defeitos. Foram apenas bons propósitos: devo ter-me revelado com freqüência egoísta e mesquinho. E esse desabrochar de sentimentos maus era a pior tortura que nos podiam infligir naquele ano terrível ${ }^{26}$.

As modificações impostas pela experiência do cárcere atingem o indivíduo na sua própria maneira de ser, portanto não poderão ser apagadas. Apenas a compreensão dos mecanismos que determinaram tais modificações torna possível liberar-se do passado. Como afirma Graciliano, "na verdade estávamos mortos, vamos ressuscitando". ${ }^{27}$
25. RAMOS, op. cit., $p$ 158, v. II.

26. Ibid., p. 37 , v. I.

27. Ibid., p. 35 , v. I. 
Em um dos últimos capítulos de sua obra, redigido como um poema em prosa, Mario Benedetti desvenda o significado do título, através das imagens que ocorrem a Santiago, solto após cinco anos de cadeia e a caminho do exílio:

La primavera es como un espejo, pero el mió tiene una esquina rota/ [...] pero aun con la esquina rota el espejo sirve la primavera sirve [...].

Habrá que volver pero a qué país a qué Uruguay/ también tendrá una esquina rota y sin embargo reflejará más realidades que cuando el espejo estaba virgen $[\ldots]^{28}$.

Findo o inverno da repressão, a primavera torna a voltar, mas não intacta. Após a experiência da tortura, o que resta de um indivíduo, e da sociedade à qual pertence, é uma imagem fragmentada, um espelho quebrado. Através dos mecanismos da memória, entre lembrança e esquecimento, é possível recompô-lo, mas sempre há de lhe faltar algum canto. Por outro lado, sua capacidade de reflexão, no duplo significado da palavra, encontra-se multiplicada. Nesse sentido, a criação literária exerce plenamente a função de ressuscitar o passado mediante um trabalho de rememoração crítica. Para que a tortura não possa mais nos reduzir ao silêncio...

Resumo: As histórias de vivência de prisioneiros políticos em tempos de repressão colocam de maneira intensa a questão da memória. Duas obras literárias latino-americanas: Memórias do cárcere, de Graciliano Ramos, e Primavera con una esquina rota, de Mario Benedetti, são analisadas neste artigo. A autora pondera que, embora nos forneça índices essenciais, a análise puramente literária não basta para abordar as experiências vividas no cárcere. Além de seu necessário enquadramento em determinados contextos históricos e políticos, considera que devemos, ao abordá-las, levar igualmente em conta os seus aspectos psicológicos, referindo-se essencialmente aos trabalhos de pesquisa pioneiros sobre os efeitos da tortura que têm sido realizados por Françoise Sironi e o centro parisiense de etnopsiquiatria Georges-Devéreux.

Palavras-chave: memória, repressão, análise literária, Françoise Sironi, GeorgesDevéreux.
Abstract: The life stories of political prisoners in repression times put, in intense manner, the issue of memory. Two Latin American literary works - Memórias do cárcere, by Graciliano Ramos, and Primavera con una esquina rota, by Mario Benedetti - are analyzed in this article. The author considers that, though it gives us essential indexes, the purely literary analysis is not enough to approach the experiences lived in jail. Besides its necessary framing in specific historical and political contexts, she thinks we must, when broaching them, also have in account its psychological aspects, referring essentially to Françoise Sironi's and Parisian Ethnopsychiatry Center Georges-Devéreux's pioneer researches on the effects of torture.

Keywords: memory, repression, literary analysis, Françoise Sironi, Georges-Devéreux. 